\title{
Enzymatic thiol-ene click reaction: an eco-friendly approach for MPEGMA-grafted modification of wool fibers
}

\author{
Pan Zhang ${ }^{\mathbf{a}, \mathbf{b}}$, Qiang Wang ${ }^{\mathbf{a}, * *}$, Jinsong Shen ${ }^{\mathbf{b}, * *}$, Ping Wang ${ }^{\mathbf{a}}$, Jiugang Yuan ${ }^{\mathbf{a}}$, Xuerong Fan ${ }^{\mathbf{a}}$

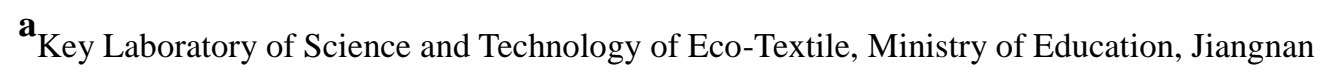 \\ University, Wuxi, Jiangsu 214122, China

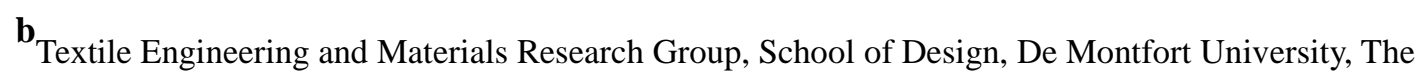 \\ Gateway, Leicester LE1 9BH, UK
}

\section{Correspondence:}

***Prof. Qiang Wang, qiangwang@jiangnan.edu.cn, +86-510-85912007.

*Prof. Jinsong Shen, jshen@dmu.ac.uk, +44-(0)-116-2577558.

\begin{abstract}
Thiol-ene click reaction has been commonly used for the modification of many materials due to its high efficiency, high selectivity and reliability. To further promote the sustainable technology for the modification of keratin-based materials, enzymatic biotechnology and thiol-ene click chemistry was integrated first time for grafting modification of wool fibers with methoxy polyethylene glycol methacrylate (MPEGMA). The wool fibers were reduced to create thiol groups and then grafted with MPEGMA through Horseradish peroxidase (HRP) -mediated thiol-ene click reaction. In order to understand the grafting mechanism of MPEGMA on wool, L-cysteine was used as a model compound for the thiol-group of the reduced wool in the current research. The structures of MPEGMA reacted with L-cysteine
\end{abstract}


and grafted on wool fabrics were investigated by FTIR, MALDI-TOF, Raman spectra, and XPS. The surface morphology, wettability, moisture penetrability and regain of modified wool fibers were also assessed. The results showed that L-cysteine reacted with MPEGMA through thiol-ene click reaction. The MPEGMA-grafted wool fabric had good surface wettability and its moisture penetrability and regain were also improved when compared with untreated wool fabric. HRP-initiated thiol-ene grafting reaction not only enrich green and sustainability of click chemistry, but also provide an alternative eco-friendly approach for modification and functionalization of keratin and keratin-containing materials.

Keywords: Wool $\cdot$ Thiol-ene $\cdot$ Horseradish peroxidase $($ HRP) $\cdot$ MPEGMA $\cdot$ Graft modification

\section{Introduction}

The thiol-ene click chemistry, the reaction of thiol groups with a wide variety of unsaturated functional groups, such as maleimides, acrylates and norbornenes, in addition to the groups with carbon-carbon double bonds, has received considerable attention in recent years because of its high efficiency, high selectivity and reliability ${ }^{1,2}$. Thiol-ene click reaction has been widely employed as the means for preparing near-perfect networks $s^{3,4}$ and films ${ }^{5}$ in the polymer/material fields due to its tolerance to many different conditions/solvents.

Recently, there has been an increasing interest in the modification of materials by using thiol-ene click reaction. MarcComí ${ }^{6}$ modified polyurethanes (PUs) by thiol-ene click coupling of thioglycerol to obtain hydrophilicity. Levine ${ }^{7}$ modified unsaturated poly[(R) -3-hydroxyalkanoates] (PHA) copolymers via thiol-ene click chemistry to gain an assortment of new functional groups and improved PHA's strength and pliability. Luo et $\mathrm{al}^{8}$ presented a 
one-step chemical way to synthesize stable graphene oxide based composite films by interfacial thiol-ene photopolymerization at room temperature, without use of any crosslinking and stabilizing agents. Furthermore, thiol-ene click reaction also has been studied for fiber modification in the textile industry. For example, $\mathrm{Yu}$ et $\mathrm{al}^{9}$ grafted hydrophilic acrylate sulfonate or acrylamide sulfonate onto wool fiber through thiol-ene click chemistry and improved the antistatic and liquid moisture management properties of wool fiber. $\mathrm{Hu}$ et a ${ }^{10}$ modified wool fiber with vinyl terminated polymers through the thiol-ene click reaction between the thiol groups in reduced wool fiber and double carbon bonds in vinyl terminated polymers, resulting in wool fabric imparted with good antibacterial, antistatic properties and hydrophilicity. Kun et $\mathrm{al}^{11}$ successfully generated robust polyhedral oligomeric silsesquioxane (POSS) -based superhydrophobic fabrics by surface modification of fibers with mercapto silanes followed by thiol-ene coupling with methacryl-heptaisobutyl POSS (MAPOSS).

As gradually increasing attention is given to the environmental pollution issues, enzymes are widely used as environmentally friendly and nontoxic biocatalysts for material modification as typical sustainable practices. Enzymatic approach exhibits great advantages over traditional chemical treatment systems, including mild reaction conditions, efficiency, environmental friendliness, and bioavailability. Horseradish peroxidase (HRP, EC1.11.1.7), an oxidoreductase obtained from the roots of horseradish, can catalyse the oxidation of electron-rich aromatic compounds including phenol and aniline to form their free radicals, leading to further polymerizations ${ }^{12,13}$. In addition, HRP also can catalyse thiols as substrates to generate thiyl radicals or disulfides ${ }^{14}$ for thiol-ene polymerization. HRP-catalysed disulfide formation has been used to construct degradable hydrogels and nanogels by Groll et al ${ }^{15}$. In 
our previous work, horseradish peroxidase was used for fiber material modification based on free-radical copolymerization. $\mathrm{Wu}$ et al used $\mathrm{HRP}$ to catalyse the free-radical copolymerization of phenol acrylamide and lignin on the surface of jute fibers, to improve the moisture absorption and wettability ${ }^{16}$; Zhou et al carried out phenol-grafting copolymerization of acrylic acid (AA) onto fibroin chains using $\mathrm{HRP} / \mathrm{H}_{2} \mathrm{O}_{2}{ }^{17}$; Xu et al activated tyrosine in wool fiber with $\mathrm{HRP} / \mathrm{H}_{2} \mathrm{O}_{2}$ and then grafted chitosan onto active wool fabrics to endow wool with anti-felting and improved antibacterial property ${ }^{18}$.

In the present work, a novel enzymatic thiol-ene click reaction has been developed for keratinous modification. This is the first time for HRP to be used as a thiol-ene reaction initiator to initiate grafting polymerization on wool fibers. The procedure of keratin fiber modification is schematically illustrated in Scheme 1. Disulfide bonds in the cuticle scales of wool fibers were reduced to thiol groups. Then the thiol groups were activated into thiyl radicals by $\mathrm{HRP} / \mathrm{H}_{2} \mathrm{O}_{2}$ system. Thiol-ene click reaction proceeds via alternating propagation and chain-transfer reactions accordingly. Hydrophilic compounds containing double carbon bonds like methoxy poly (ethylene glycol) methacrylate (MPEGMA) was grafted on wool fiber through thiol-ene click reaction initiated by HRP. It was found that wool fiber can be modified by MPEGMA through thiol-ene click reaction under the HRP catalysis, which provides a novel and environment-friendly path for grafting modification of wool or keratin and keratin-contained materials. 


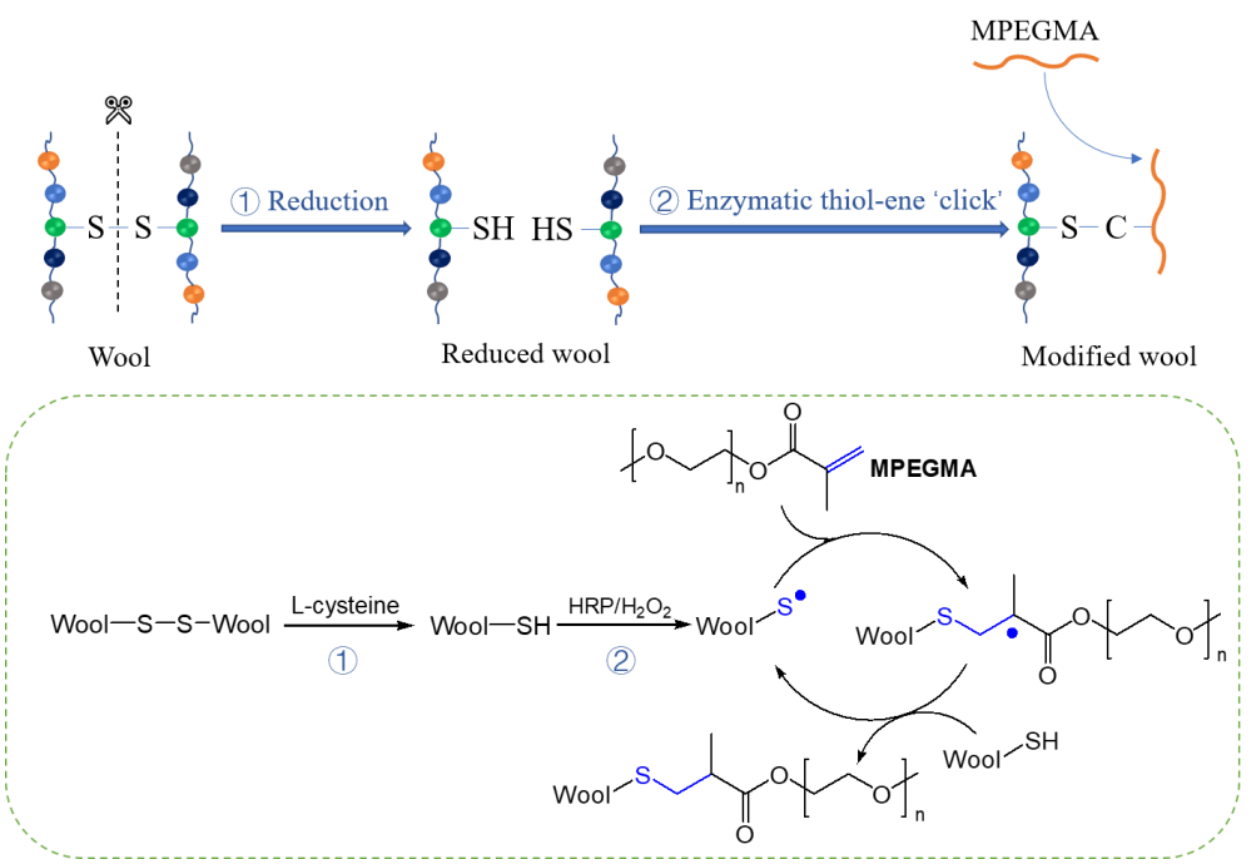

Scheme 1. Schematic illustration of enzymatic thiol-ene 'click' reaction for MPEGMA-grafted modification of wool fibers

\section{Experimental Section}

\section{Materials}

Wool fibers $(24 \mu \mathrm{m})$ and wool fabric (Gabardine, 56/2 Nm, $220 \mathrm{~g} / \mathrm{m}^{2}$ ) were provided by Wuxi Xiexin Woolen Textile Co., Ltd. Horseradish peroxidase (HRP, lyophilized powder, $300 \mathrm{U} / \mathrm{mg}$ ) and methoxy poly (ethylene glycol) methacrylate (MPEGMA, average Mn 300) were purchased from Sigma-aldrich (China). All other chemicals used were of analytical grade.

\section{Modification of L-cysteine with MPEGMA}

Methoxy poly(ethylene glycol) methacrylate (MPEGMA) (0.2 g, $0.08 \mathrm{mmol}$ ene group) and L-cysteine (19.35 mg, $0.16 \mathrm{mmol}$ thiol group) were added to acetic/sodium acetate buffer $(0.2 \mathrm{~mol} / \mathrm{L})$ containing HRP $(1 \mathrm{mg} / \mathrm{ml}, 0.084 \mathrm{~mL}, 25 \mathrm{U})$ in a shaking bath at $0{ }^{\circ} \mathrm{C}$ for $30 \mathrm{~min}$ 
under nitrogen gas. Then $\mathrm{H}_{2} \mathrm{O}_{2}(20 \mu \mathrm{L}, 3 \%$ (w/v)) was injected into the mixture solution and the temperature was increased to $37^{\circ} \mathrm{C}$. After an hour reaction, the mixture was precipitated with acetone and centrifuged three times. The sediment was vacuum dried at $30{ }^{\circ} \mathrm{C}$.

\section{Pretreatment and reduction of wool fabric}

Wool fabrics were extracted with acetone for $24 \mathrm{~h}$ using Soxhlet extractor to remove the dirt and surface lipid before use. The wool fabric (5 g) was pre-treated for $1 \mathrm{~h}$ in $250 \mathrm{~mL}$ solution of L-cysteine $(1.5 \mathrm{~g})$ at $60{ }^{\circ} \mathrm{C}$ to create thiol groups. The fabric sample was then washed with water and placed in anhydrous ethanol under ultrasonic oscillation for $30 \mathrm{~min}$. The degree of reduction was determined by measuring the number of thiol groups spectrophotometrically at a wavelength of $412 \mathrm{~nm}$ using Ellman's reagent ${ }^{19}$.

\section{Grafting of MPEGMA onto wool fabric}

The pre-treated wool fabrics ( $1 \mathrm{~g}, 0.04 \mathrm{mmol}$ thiol group) were incubated in acetic/ sodium acetate buffer $(0.2 \mathrm{~mol} / \mathrm{L}, 200 \mathrm{~mL})$ at $\mathrm{pH} 4.5$ containing MPEGMA $(10 \mathrm{mg} / \mathrm{ml})$ and HRP (1 $\mathrm{mg} / \mathrm{ml}, 0.84 \mathrm{~mL}, 250 \mathrm{U}$ ) in a shaking bath at $0{ }^{\circ} \mathrm{C}$ for 30 min under nitrogen gas. Then $\mathrm{H}_{2} \mathrm{O}_{2}$ $(200 \mu \mathrm{L}, 3 \%(\mathrm{w} / \mathrm{v}))$ was injected into the treatment solution and the temperature was increased to $37{ }^{\circ} \mathrm{C}$. After 12 hours reaction, the finished fabric was washed and dried at 30 ${ }^{\circ} \mathrm{C}$.

\section{Preparation of MPEGMA-adsorbed wool fabric}

For comparison, the pre-treated wool fabrics $(1 \mathrm{~g})$ were incubated in acetic and sodium acetate buffer $(0.2 \mathrm{~mol} / \mathrm{L}, 200 \mathrm{~mL})$ containing only MPEGMA $(10 \mathrm{mg} / \mathrm{ml})$ in a shaking bath at $0{ }^{\circ} \mathrm{C}$ for $30 \mathrm{~min}$ under nitrogen gas. Then the temperature of reaction was increased to 37 ${ }^{\circ} \mathrm{C}$. After 12 hours, the wool was washed with water and dried at $30{ }^{\circ} \mathrm{C}$. 
The graft yield (GY) of MPEGMA on wool fibers was determined by monitoring the changes in the concentrations of MPEGMA in the treatment solution, before and after the grafting reaction. The concentrations of MPEGMA were measured according to GB/T 12005.3-1989. $10 \mathrm{~mL}$ potassium bromate-potassium bromide solution $(0.1 \mathrm{~mol} / \mathrm{L})$ and $5 \mathrm{~mL}$ hydrochloric acid (50\% v/v) were added in $5 \mathrm{~mL}$ test solution. Then the mixture was sealed and shacked well in dark. After $30 \mathrm{~min}, 5 \mathrm{~mL}$ potassium iodide solution $(20 \% \mathrm{w} / \mathrm{v})$ was added and titrated with sodium thiosulfate solution $(0.05 \mathrm{~mol} / \mathrm{L})$. When the color of the mixture became light yellow, $2 \mathrm{~mL}$ starch indicator was added and the sodium thiosulfate solution was continuously added until the color of the mixture turning blue. The dosage of sodium thiosulfate solution was recorded. The blank sample was tested as control. The graft yield was calculated by the Equation (1).

$$
G Y=100 \times\left(V_{2}-V_{1}\right) / V_{O}
$$

Where $V_{0}$ is the sodium thiosulfate solution dosage of the original MPEGMA; and $V_{1}$ and $V_{2}$ represent the sodium thiosulfate solution dosage of the residual solutions with and without the addition of HRP, respectively.

\section{Characterization of L-cysteine grafted MPEGMA}

FTIR spectra of MPEGMA, L-cysteine and MPEGMA grafted with L-cysteine using $\mathrm{KBr}$ pellet method were recorded on a Nicolet IS10 Infrared Spectrophotometer (Thermo Nicolet, USA) in the wavelength range $500-4000 \mathrm{~cm}^{-1}$ at a resolution of $4 \mathrm{~cm}^{-1}$ and 32 scans per sample.

Matrix-assisted laser-desorption/ionization time- of-flight mass spectra (MALDI-TOF MS) of the MPEGMA, self-polymerized MPEGMA and L-cysteine-grafted MPEGMA were 
obtained using a Bruker Proflex Instrument equipped with a nitrogen laser (Smart Beam II, modified Nd: YAG laser). Data collection and processing were performed by flexControl and flexAnalysis version 3.3 software.

\section{Characterization of MPEGMA-grafted wool}

The surface morphology of wool samples was studied using a SU-1510 Scanning Electron Microscope (Hitachi, Japan) that operated at a typical accelerating voltage of $5 \mathrm{kV}$. Wool fabrics were sputter-coated with a thin layer of gold prior to scanning.

X-ray photoelectron spectroscopy (XPS) analysis of wool samples was carried out using an RBD upgraded PHI-5000C ESCA system (Perkin Elmer). The general spectra in the range 0 $1100 \mathrm{eV}$ and narrow spectra at high resolution for all elements were recorded.

Raman spectra were obtained at a resolution of $4 \mathrm{~cm}^{-1}$ using an inVia Reflex Raman spectrometer (Renishaw, British). Fabric samples were held on a mirrored backing. For fabrics, 512 scans were collected at a laser power $500 \mathrm{~mW}$. To improve the signal to noise ratio, three spectra collected from different areas of each fabric were co-averaged to produce a final spectrum for analysis. A Blackman-Harris 3-term Apodization function was used.

\section{Physical and mechanical properties of MPEGMA-grafted wool fabric}

Tensile strength of wool fabrics was determined according to ISO13934.1, using a YG(B) 026D - 250 Fabric Tensile Strength Tester (Wenzhou Darong, China). The results were expressed as breaking strength (maximum load) in the warp direction. The alkali solubility of wool fabric was evaluated using the standard method ASTM D1283-85 (Kiro 2017). Wool fabric oven-dried at $105{ }^{\circ} \mathrm{C}$ for 15 minutes was weighed as the original weight and then was incubated in a beaker containing $100 \mathrm{~mL}$ of $0.1 \mathrm{~mol} / \mathrm{L}$ sodium hydroxide at $65^{\circ} \mathrm{C}$ for $1 \mathrm{~h}$. The 
residues were filtered and rinsed six times with distilled water and dried in an oven at $105{ }^{\circ} \mathrm{C}$ for $1 \mathrm{~h}$ and weighted. Afterwards, the alkali solubility of the samples was calculated as a percentage of the original weight. Values are the average of three replicates.

\section{Shrink-resistance property of MPEGMA-grafted wool fabric}

The shrink-resistance of MPEGMA-grafted wool fabric was determined according to IWTO-20-69 (E) using a YH-A cup rotary quick test infrared dyeing machine (Yuanhong Dying, China). Before the measurements, wool fabric samples were conditioned to moisture equilibrium in a standard atmosphere with a relative humidity of $65 \pm 5 \%$ at $21 \pm 1{ }^{\circ} \mathrm{C}$ for 24

h. Then $1 \mathrm{~g}+0.005 \mathrm{~g}$ wool fiber was put into a steel cup with $50 \mathrm{~mL}$ distilled water. The steel pot with wool fiber was agitated in the machine at $40{ }^{\circ} \mathrm{C}$ for $30 \mathrm{~min}$. The felting ball was dried at $50{ }^{\circ} \mathrm{C}$. Afterwards, the average density of felting ball was calculated by the Equation (2). For each sample, results were recorded from the average of three samples.

$$
\delta=6 /\left(\pi d_{m}^{3}\right)
$$

Where $\delta$ is the average density of felting ball $\left(\mathrm{g} / \mathrm{cm}^{3}\right)$ and $\mathrm{d}$ is the average diameter of felting ball $(\mathrm{cm})$.

\section{Surface wettability of MPEGMA-grafted wool fabric}

The surface wettability of wool fabrics was evaluated by water contact angle measurements and wetting time. Before the measurements, wool fabric samples were conditioned to moisture equilibrium in a standard atmosphere with a relative humidity of $65 \pm 5 \%$ at $21 \pm 1$ ${ }^{\circ} \mathrm{C}$. Then, the contact angle was measured using a JC2000D4 Contact Angle Meter (Zhongchen, China). For each sample, readings were recorded from five spots and averaged the results. The wetting time was recorded when the droplets completely infiltrated into the 
wool fabric. Measurements for each sample were made 5 times, and the results were averaged.

To access the durability to washing of the grafting treatment, the treated wool fabrics were subjected to a washing test using a Launder-O-Meter, where the fabrics were at $30{ }^{\circ} \mathrm{C}$ for 45 min at the liquor to fabrics ratio of 1: 20 (o.w.f, on weight of fabric). Then the fabrics were dried at room temperature.

\section{Moisture penetrability and regain of MPEGMA-grafted wool fabric}

According to GB/T 12704.1-2009 (Textiles-Test method for water-vapour transmission of fabrics-Part 1: Desiccant method), the wool fabric samples were conditioned to moisture equilibrium in a standard atmosphere with a relative humidity of $65 \pm 5 \%$ at $21 \pm 1{ }^{\circ} \mathrm{C}$ before the measurements. Then the wool fabrics were mounted on the top of the moisture penetrable cups containing anhydrous calcium chloride and weighted as original weight. Moisture penetrable cups with wool fabrics were put in a test box at $38 \pm 2{ }^{\circ} \mathrm{C}, 90 \pm 2 \% \mathrm{RH}$ for $1 \mathrm{~h}$ and weighted. The moisture penetrability was calculated by the Equation (3). For each sample, results were recorded from the average of three samples.

$$
\mathrm{WVT}=\left(\Delta \mathrm{m}-\Delta \mathrm{m}^{\prime}\right) /(\mathrm{A} \cdot \mathrm{t})
$$

Where WVT is the moisture penetrability of wool fabric; $\Delta \mathrm{m}$ is the weight change of the sample; $\Delta \mathrm{m}^{\prime}$ is the weight change of blanket sample; A represents tested area; $\mathrm{t}$ is testing time.

Moisture regain of wool fabrics was measured according to GB/T 6500-2008 (test method for moisture regains of hair fibers-oven method). Wool fabric samples were conditioned to moisture equilibrium in a standard atmosphere with a relative humidity of $65 \pm 5 \%$ at $21 \pm 1$ ${ }^{\circ} \mathrm{C}$ and weighted as original weight. Then fabrics were dried in $105 \pm 2{ }^{\circ} \mathrm{C}$ until the wool 
samples reached at constant weight. The time for each sample weighting should not be over $15 \mathrm{~s}$. The moisture regains were calculated by the Equation (4). For each sample, results were recorded from the average of three samples.

$$
\mathrm{R}=100 \times\left(\mathrm{m}-m_{0}\right) / m_{0}
$$

Where $\mathrm{R}$ represents the moisture regain of wool sample; $\mathrm{m}$ and $\mathrm{m}_{0}$ are the weight of wool sample before and after drying.

\section{Results and Discussion}

\section{Characterization of MPEGMA and its coupling reaction with L-cysteine}

Wool fibres contain disulfide bond in the surface cuticle layers. When wool fibres are reduced, the disulfide bonds are broken to form thiol groups. Considering the fact that L-cysteine is a low molecular weight (121 Da) water-soluble amino acid with thiol groups, which are similar to the thiol groups in the reduced wool fiber, L-cysteine was chosen as the model compound for wool. The coupling reaction between L-cysteine and MPEGMA was studied in order to understand the grafting mechanism of MPEGMA onto wool via thiol-ene click chemical reaction. Structural characteristics of MPEGMA and further coupling with L-cysteine were investigated by FTIR spectroscopy and MALDI-TOF MS.

$$
\text { FT-IR spectra of MPEGMA, L-cysteine (CYS) and L-cysteine-coupled }
$$
MPEGMA(MPEGMA-CYS) are shown in Fig.1. The characteristic absorption peaks at 1592 $\mathrm{cm}^{-1}$ and $1539 \mathrm{~cm}^{-1}$ are caused by $\mathrm{C}=\mathrm{O}$ stretching vibration (amide $\mathrm{I}$ band) and $\mathrm{N}-\mathrm{H}$ bending vibration (amide II band) in the peptide bond, which are the typical peaks of proteins ${ }^{20}$. The characteristic absorption peaks of MPEGMA at $1728 \mathrm{~cm}^{-1}, 1637 \mathrm{~cm}^{-1}$ and $1126 \mathrm{~cm}^{-1}$ are respectively attributed to $\mathrm{C}=\mathrm{O}$ stretching vibration, $\mathrm{CH}_{2}=\mathrm{CH}$ - stretching vibration and 
C-O-C stretching vibration ${ }^{21}$. The spectrum of L-cysteine is similar to the spectrum of L-cysteine-coupled MPEGMA. There are peaks of $\mathrm{C}=\mathrm{O}$ stretching vibration (amide $\mathrm{I}$ band) and $\mathrm{N}-\mathrm{H}$ bending vibration (amide II band) at $1592 \mathrm{~cm}^{-1}$ and $1538 \mathrm{~cm}^{-1}$. In addition, new peaks appeared at $1728 \mathrm{~cm}^{-1}$ and $1126 \mathrm{~cm}^{-1}$ which correspond to $\mathrm{C}=\mathrm{O}$ and $\mathrm{C}-\mathrm{O}-\mathrm{C}$ in the spectrum of L-cysteine-coupled MPEGMA, which confirms covalent cross link formed between L-cysteine and MPEGMA.

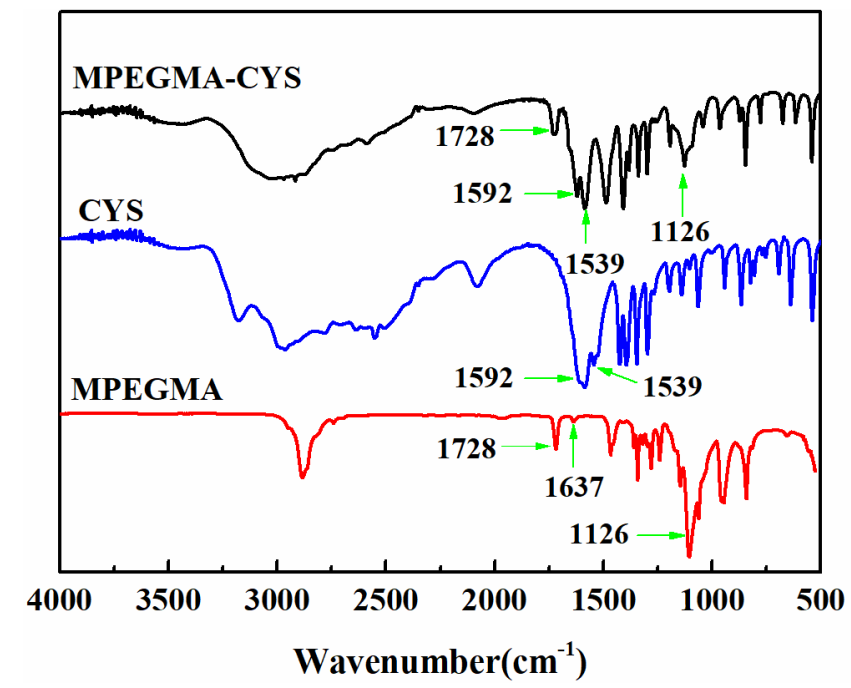

Fig.1. FT-IR spectra of MPEGMA, L-cysteine (CYS) and L-cysteine-grafted

\section{MPEGMA(MPEGMA-CYS).}

The MALDI-TOF mass spectra of MPEGMA, MPEGMA mixed with HRP and L-cysteine-coupled MPEGMA were analysed to confirm the findings of FTIR spectroscopy. MALDI-TOF MS was employed successfully for the characterization of biomolecules and synthetic polymers, which provided highly reliable information of the molecular weight of the polymer $^{22}$. After coupling MPEGMA with L-cysteine, the insoluble deposit was removed and the residual bath was further examined using MALDI-TOF mass. The possible mass-to-charge $(\mathrm{m} / \mathrm{z})$ ratios in the range of 250-600 Da for different copolymers are listed in Table 1. For MPEGMA, the possible numbers of repeat units are 4, 5, 6, 7 and the 
mass-to-charge $(\mathrm{m} / \mathrm{z})$ ratios are at 298.6, 342.9, 386.8, 430.9, respectively. Considering MPEGMA might form dimers and trimmers, the MPEGMA mixed with HRP in the buffer without L-cysteine. It can be seen in Fig.2 that there are four peaks at 299.2, 343.0, 386.8, 431.1, which are the same to the spectrum of MPEGMA. Thus, there are no self-polymerization in MPEGMA. Furthermore, the $\mathrm{m} / \mathrm{z}$ of 396 (4MPEGMA+CYS), 440 (5MPEGMA+CYS), 484 (6MPEGMA+CYS) Da represent the MPEGMA coupled with L-cysteine. There were marginal differences observed between the predicted and detected molecular weights, due to the presence of buffer salts and detergents in the process of testing that affect the intensity and quality of the signals ${ }^{23}$. Based on results from FTIR and MALDI-TOF mass, thiol-ene reaction between MPEGMA and L-cysteine could be evidently confirmed, implying that HRP could initiate the grafting modification of wool with MPEGMA through thiol-ene click reaction. 

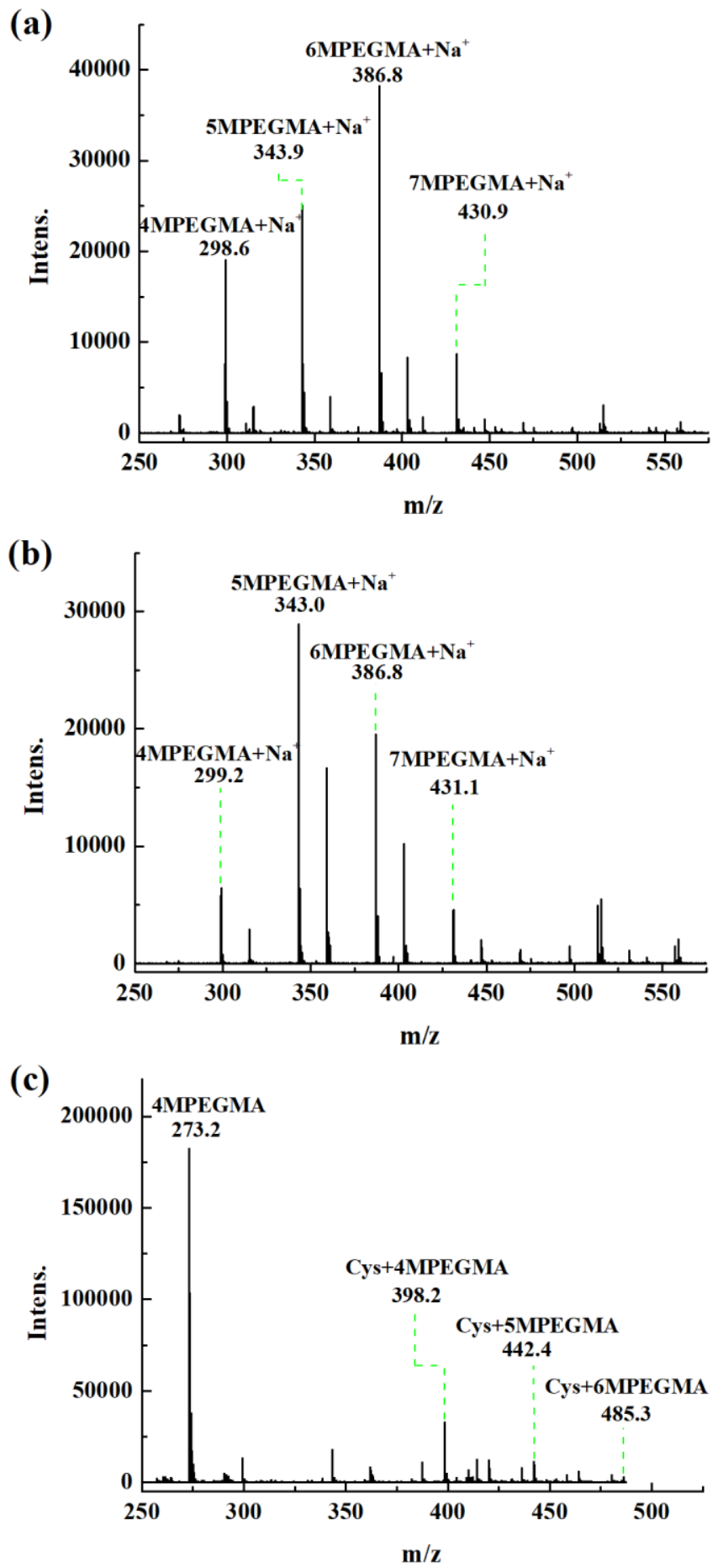

Fig.2. MALDI-TOF mass spectra of (a) MPEGMA, (b) MPEGMA mixed with HRP and (c) MPEGMA grafted with L-cysteine. 
Table 1 The possible mass-to-charge (m/z) assignments of MPEGMA, MPEGMA mixed with HRP and L-cysteine-coupled MPEGMA samples.

\begin{tabular}{|c|c|c|}
\hline \multicolumn{2}{|r|}{ m/z(Da) } & \multirow{2}{*}{ Predicted compound $\left(\mathrm{ESI}^{+}\right)$} \\
\hline Detected & Predicted & \\
\hline $298,342,386,430$ & $298.6,342.9,386.8,430.9$ & $\begin{array}{l}\text { 4MPEGMA }\left(\mathrm{Na}^{+}\right), \text {MMPEGMA }\left(\mathrm{Na}^{+}\right) \text {, } \\
6 \mathrm{MPEGMA}\left(\mathrm{Na}^{+}\right), 7 \mathrm{MPEGMA}\left(\mathrm{Na}^{+}\right)\end{array}$ \\
\hline $298,342,386,430$ & $299.2,343.0,386.8,431.1$ & $\begin{array}{l}\text { 4MPEGMA }\left(\mathrm{Na}^{+}\right), \text {MMPEGMA }\left(\mathrm{Na}^{+}\right) \text {, } \\
\text { 6MPEGMA }\left(\mathrm{Na}^{+}\right), 7 \mathrm{MPEGMA}\left(\mathrm{Na}^{+}\right)\end{array}$ \\
\hline $396,440,484$ & $398.2,442.4,485.3$ & $\begin{array}{l}\text { 4MPEGMA+CYS, 5MPEGMA+CYS, } \\
\text { 6MPEGMA+CYS }\end{array}$ \\
\hline
\end{tabular}

\section{Characterization of MPEGMA-grafted wool fibers}

The wool fabrics were treated by L-cysteine to break the disulfide bonds into thiol groups. The content of thiol group is $0.04 \mathrm{mmol} / \mathrm{g}$ after L-cysteine pretreatment from the testing by spectrophotometry at a wavelength of $412 \mathrm{~nm}$ using Ellman's reagent. Graft yields of MPEGMA onto wool fabrics were determined by measuring changes in concentrations of MPEGMA in the treatment solution before and after treatments. The change in concentration of MPEGMA for the reaction of wool with MPEGMA in the absence of HRP reached 3.36\%, which occurred mainly due to the adsorption of MPEGMA onto wool fabrics via hydrogen bonds and van der Waals forces. The graft yield for the wool grafted with MPEGMA in the presence of HRP went up to $6.83 \%$, suggesting that a higher amount of MPEGMA was covalently bonded to the wool surface. 
SEM images in Fig. 3 show the surface characteristic of untreated wool fiber (a), L-cysteine-pretreated wool fiber (b), MPEGMA-adsorbed wool fiber (c), and MPEGMA-grafted wool fiber (d). The surface layer scales of untreated wool fiber (Fig. 3a) appeared very clear and intact, but the surface of the pretreated wool sample (Fig. 3b) showed slight damage to the cuticle scales. The partial breaking of the disulfide bonds in the keratin by the reduction pre-treatment of wool fiber could cause slight damage to the cuticle layer, resulting in formation of the broken cuticle fragments on the surface of the wool fibers. MPEGMA-adsorbed wool fibre sample (Fig. 3c) showed fine particles appeared on the surface of the fibers due to the adsorbed MPEGMA. The amount of MPEGMA on the MPEGMA-grafted wool sample is almost double to the amount on the MPEGMA-adsorbed wool sample. Therefore, it was found that the surface coating was formed as showed in the SEM image of MPEGMA-grafted sample (Fig. 3d) and the cuticle scales of wool were covered by the grafted MPEGMA coating. These results demonstrate not only the adsorption of MPEGMA onto wool fibers but also coating through covalent bonding of MPEGMA on the surface of wool fiber which was achieved by wool reducing pretreatment and subsequent MPEGMA grafting. 


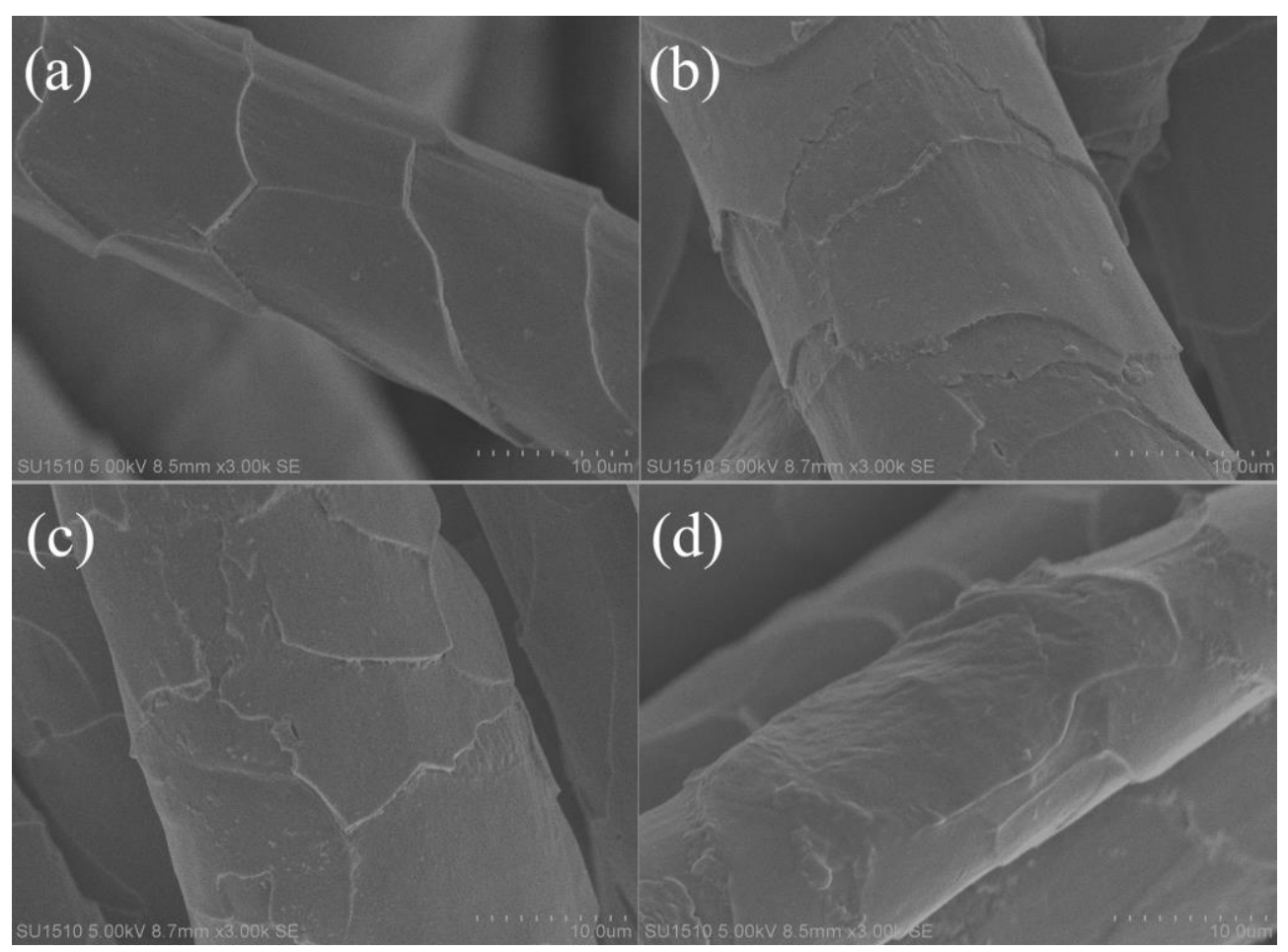

Fig.3. Surface morphologies of untreated wool (a), L-cysteine-pretreated wool (b),

MPEGMA-adsorbed wool (c), and MPEGMA-grafted wool (d).

Raman spectra of untreated wool (A), L-cysteine-pretreated wool (B), MPEGMA-adsorbed wool (C), and MPEGMA-grafted wool (D) are shown in Fig. 4. Fig. 4c shows the S-H stretching region of the spectra, while the low-frequency region is shown in Fig. 4a. Compared to the untreated wool fiber, the S-H stretching mode could be observed at $2573 \mathrm{~cm}^{-1}$ in the samples of L-cysteine-pretreated wool and MPEGMA-adsorbed-wool ${ }^{24}$. In addition, the S-S stretching vibration reduced by $55 \%$ in the spectra of L-cysteine-pretreated wool and MPEGMA-adsorbed-wool indicating that disulphide bonds were partially broken after treatment of wool with L-cysteine. However, the S-H stretching disappeared in the spectrum of MPEGMA-grafted wool. The loss in S-H intensity is not accompanied by an increase in intensity of the $\mathrm{S}-\mathrm{S}$ stretching vibration $\left(508 \mathrm{~cm}^{-1}\right)$ suggesting that disulfide bonds are not being reformed. The changes of S-S stretching and S-H stretching intensity 
demonstrated MPEGMA was grafted onto wool fiber through thiol-ene click reaction which could be catalysed by HRP.
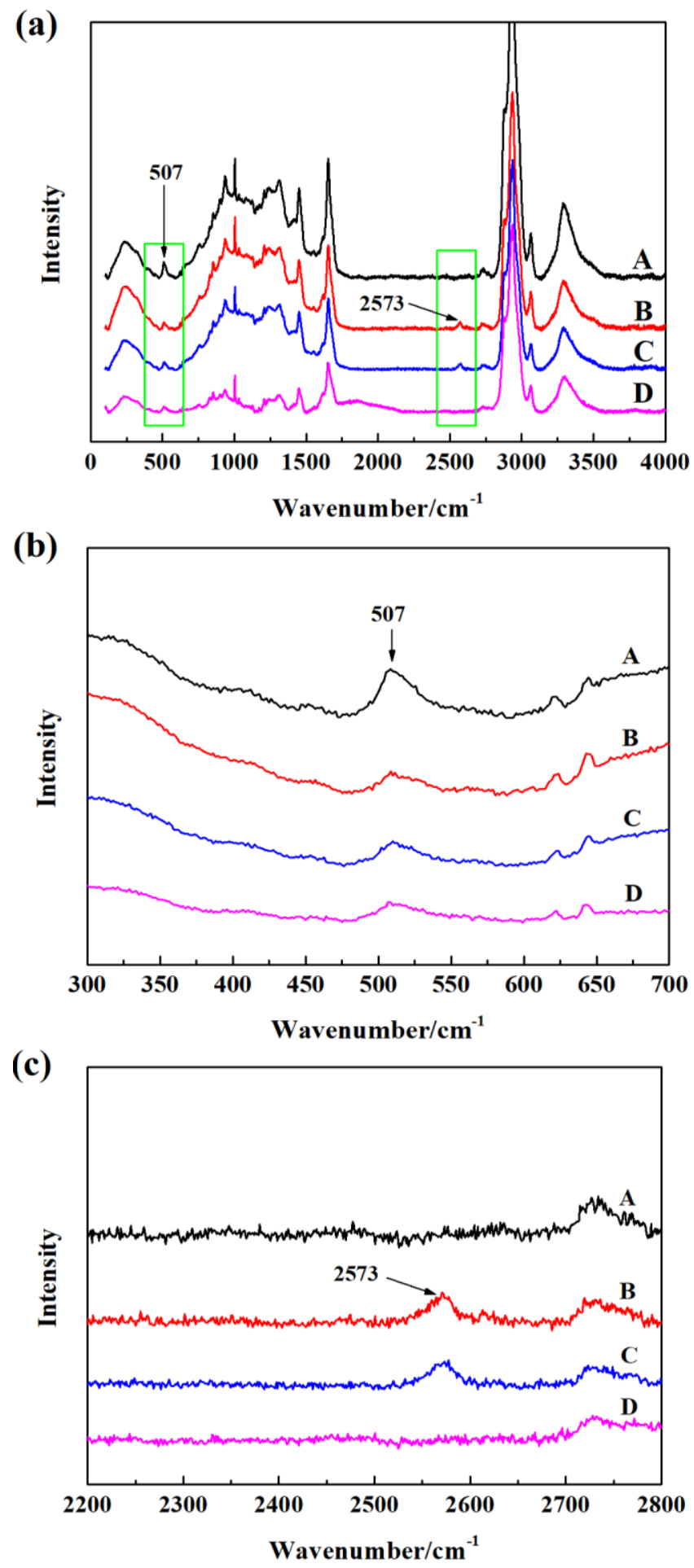

Fig.4. Raman spectra of untreated wool (A), L-cysteine-pretreated wool (B), MPEGMA-adsorbed wool (C), and MPEGMA-grafted wool (D). 
Surface elemental compositions $(\mathrm{C}, \mathrm{O}, \mathrm{N}$ and $\mathrm{S}$ ) of wool fabrics were determined by XPS analysis. The results are shown in Fig. 5 and Table 2. According to the XPS spectra of wool fabrics (Fig. 5), four characteristic peaks can be observed in the range of 0-600e V of wool XPS energy spectrum for C 1s peak (285e V), N 1s peak (400e V), O 1s (532e V) and S $(164 \mathrm{e} V)^{25,26}$. Due to the presence of the lipid layer, the $\mathrm{C}$ content of the wool fiber surface is $85.05 \%$, which is much higher than the C content in the bulk of the wool (about 50\%) ${ }^{27}$. Compared with untreated wool, the $\mathrm{C} / \mathrm{N}$ and $\mathrm{C} / \mathrm{S}$ ratios of L-cysteine-pretreated wool decreased, showing the content of $\mathrm{C}$ element was reduced after L-cysteine-pretreatment. The $\mathrm{C} / \mathrm{N}$ and $\mathrm{C} / \mathrm{S}$ ratios of wool fabrics increased after the treatment with MPEGMA. This might be because there are no $\mathrm{N}$ and $\mathrm{S}$ elements in the structure of MPEGMA. After finishing with MPEGMA, the surface of wool fabric should have adsorbed MPEGMA. Furthermore, the $\mathrm{C} / \mathrm{N}$ and $\mathrm{C} / \mathrm{S}$ ratios of MPEGMA-grafted wool are higher than that of MPEGMA-adsorbed wool, suggesting that there are more MPEGMA on the surface of wool fabric. The reason might be that HRP could catalyse thiol-ene click reaction and the double carbon bonds in the structure of MPEGMA could have thiol-ene click reaction with thiol groups in the pretreated wool fabric. The covalent crosslinking between MPEGMA and wool fiber make more MPEGMA up taken on the surface of MPEGMA-grafted wool than that of MPEGMA-adsorbed wool.

Based on the results from Raman spectra and XPS analysis, the disulfide bonds in wool fiber were reduced to thiol groups and the thiol-ene click reaction between MPEGMA and reduced wool could be evidently confirmed, implying that HRP has initiated the grafting modification of wool with MPEGMA through thiol-ene click reaction. 

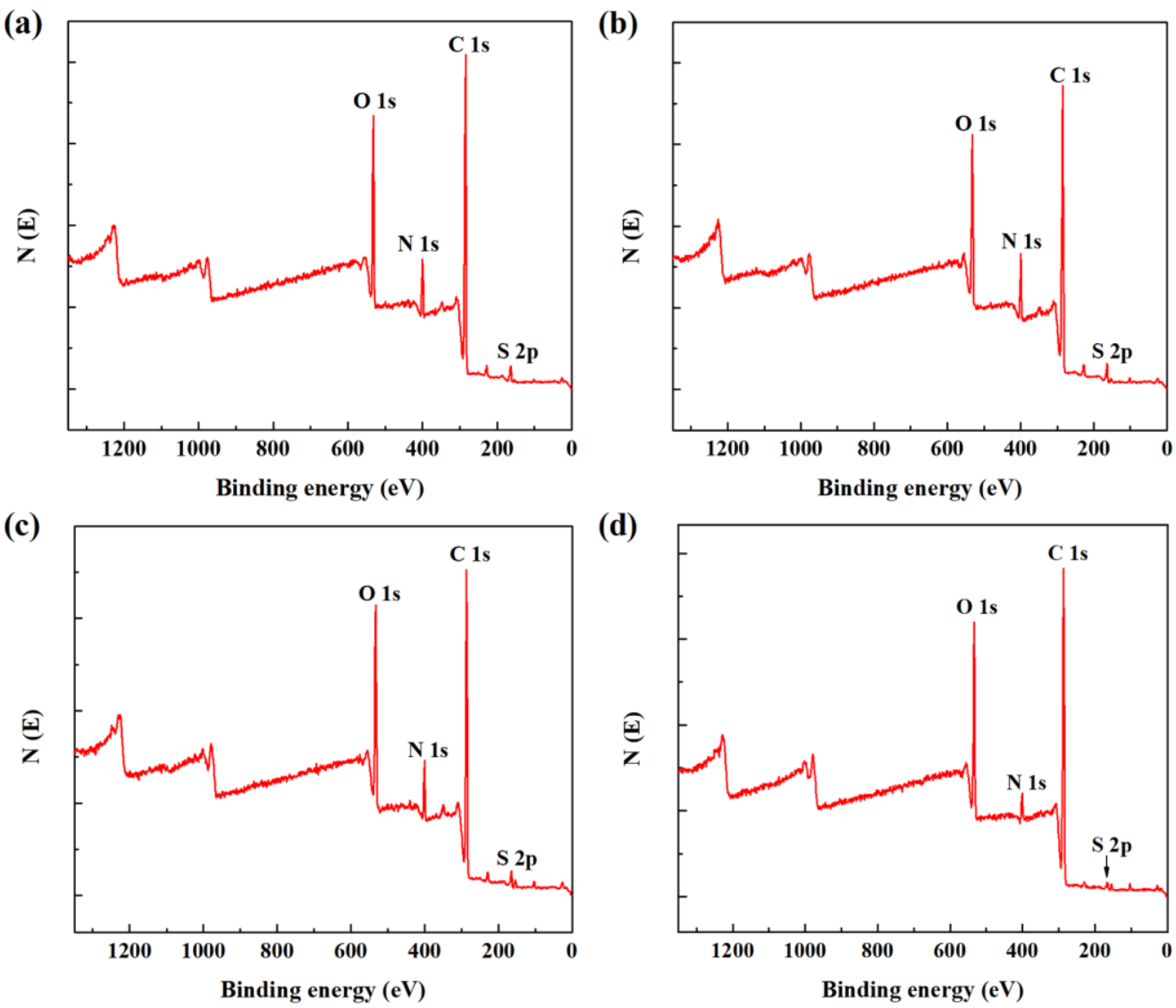

Fig.5. XPS spectra of the untreated wool(a), L-cysteine-pretreated wool (b), MPEGMA-adsorbed wool (c), and MPEGMA-grafted wool (d).

Table. 2. Surface element content of the untreated wool, L-cysteine-pretreated wool, MPEGMA-adsorbed wool, and MPEGMA-grafted wool

\begin{tabular}{cccccccc}
\hline \multirow{2}{*}{ Sample } & \multicolumn{3}{c}{ Atom conc.\% } & \multicolumn{5}{c}{ Atomic ratio } \\
\cline { 2 - 8 } & $\mathrm{C}$ & $\mathrm{N}$ & $\mathrm{O}$ & $\mathrm{S}$ & $\mathrm{C} / \mathrm{N}$ & $\mathrm{O} / \mathrm{C}$ & $\mathrm{C} / \mathrm{S}$ \\
\hline $\begin{array}{c}\text { Untreated wool } \\
\text { L-cysteine-pretr }\end{array}$ & 74.96 & 7.24 & 16.38 & 1.44 & 10.35 & 0.22 & 52.06 \\
eated wool & 71.5 & 9.24 & 16.98 & 2.29 & 7.73 & 0.24 & 31.22 \\
$\begin{array}{c}\text { MPEGMA-adso } \\
\text { rbed wool }\end{array}$ & 72.71 & 7.95 & 18.25 & 1.1 & 9.14 & 0.25 & 66.1 \\
$\begin{array}{c}\text { MPEGMA-graft } \\
\text { ed wool }\end{array}$ & 76.97 & 3.71 & 18.46 & 0.97 & 20.75 & 0.24 & 79.35 \\
\hline
\end{tabular}




\section{Physical and mechanical properties of MPEGMA-grafted wool fabric}

The physical and mechanical properties of the treated wool fabrics were assessed and the results are presented in Table 3. The tensile strength of the treated wool fabrics showed a general decline compared with untreated fabric. This was because wool fabric had been slightly damaged especially in the cuticle surface of the fiber during reduction pretreatment. However, the tensile strength of MPEGMA-grafted fabric remained higher than that of the MPEGMA-adsorbed wool fabric. That might be due to the fact that MPEGMA could form a coating layer on the surface of wool fiber. MPEGMA was also grafted onto the wool fabric through the cross-linking of protein molecules, resulting in the increase in the strength of wool fabric. Thus, the polymerization of MPEGMA on wool fiber surface could strengthen the wool fabric. In order to assess the potential damage of the treated wool fabric further, the alkali solubility was tested. The alkali solubility of wool fabrics undergoing different treatments (see Table 3) draws the same conclusion as the above-mentioned tensile strength of the treated wool fabrics. The alkali solubility of MPEGMA-absorbed wool is higher than that of MPEGMA-grafted wool. It could be further confirmed that the thiol-ene reaction between wool and MPEGMA leading to surface coating actually recovered some extent of the wool damage caused by the reduction during the pretreatment of wool. There was no obvious change in the whiteness of the wool fabric before and after treatment. Moreover, wool fabric after modified with MPEGMA was softer than untreated wool fabric indicating that the treatment of MPEGMA could improve the handle of wool fabric. 
Table. 3. Tensile strength and alkali solubility of wool fabric

\begin{tabular}{lll}
\hline Fabric Sample & Tensile strength $(\mathrm{N})$ & Alkali solubility $(\%)$ \\
\hline Untreated wool & $578.3 \pm 2.31$ & $4.83 \pm 0.55$ \\
Pre-treated wool & $451.4 \pm 3.37$ & $5.33 \pm 0.59$ \\
MPEGMA-adsorbed wool & $493.9 \pm 3.77$ & $7.04 \pm 0.64$ \\
MPEGMA-grafted wool & $510.8 \pm 3.48$ & $6.42 \pm 0.71$ \\
\hline
\end{tabular}

\section{Shrink-resist property of MPEGMA-grafted wool fabric}

The wool fibers could felt into a fiber ball at the wet condition under constant agitation.

The higher the density of the fiber ball formed, the worse felting property of the wool fiber. Shrink-resist property of modified wool fiber is showed in Fig.6. The density of untreated wool fiber felting ball is the highest among that of the four samples tested. This indicates that the shrink-resist property of untreated wool fiber is the worst. The densities of MPEGMA-adsorbed wool fiber felting ball and MPEGMA-grafted wool fiber felting ball are better than that of untreated wool fiber felting ball and L-cysteine-pretreated wool fiber felting ball. This is suggested that shrink-resist property of modified wool fiber was improved by MPEGMA grafting. Because MPEGMA as a hydrophilic macromolecular compound could form a thin film on the surface of wool fibers, resulting in the better shrink-resist property of wool fiber. This is consistent with the results of surface morphology. Additionally, the density of MPEGMA-grafted wool fiber felting ball is lower than that of MPEGMA-adsorbed wool fiber felting ball. This might be because that wool fiber could absorb MPEGMA through hydrogen bonds and van der Waals forces, but there are extra covalent linkages between MPEGMA and wool fiber in MPEGMA-grafted wool. Therefore, 
the amount of MPEGMA in MPEGMA-grafted wool fiber is more than that of MPEGMA-adsorbed wool fiber. Therefore, shrink-resist property of MPEGMA-grafted wool fiber is better than that of MPEGMA-adsorbed wool fiber.

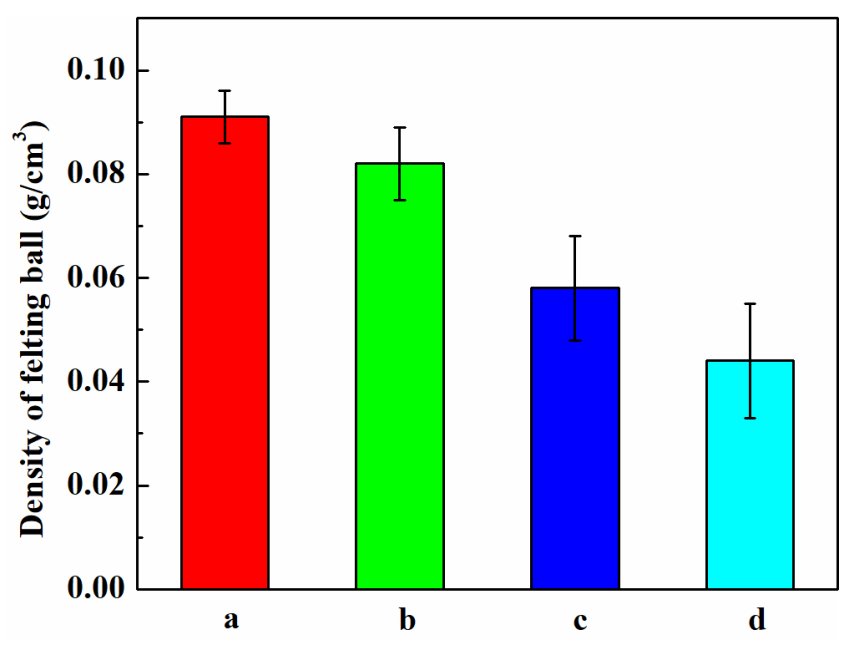

Fig. 6. Felting ball density of the untreated wool (a), L-cysteine-pretreated wool (b), MPEGMA-adsorbed wool (c), and MPEGMA-grafted wool (d).

\section{Wetting properties of MPEGMA-grafted wool fabric}

Water contact angle was tested on the MPEGMA-grafted wool samples as showed in Fig. 7. There are no evident changes of the contact angles of untreated wool and L-cysteine-pretreated wool after these fabric samples were washed 10 times. The contact angle of unwashed MPEGMA-adsorbed wool fabric is $0{ }^{\circ}$. This shows that the MPEGMA-grafted wool fabric has a good hydrophilic surface property. Its wetting time of unwashed MPEGMA-adsorbed wool fabrics (Fig.8) is 0.05 min. After washed 10 times, the contact angle of this fabric returned back to $123.17^{\circ}$ and wetting time increased to $26.92 \mathrm{~min}$. This might be due to the adsorbed MPEGMA washed away. In the preparation of the 
MPEGMA-adsorbed wool fabric, there were no HRP added. Thus, the linkage between MPEGMA and wool fiber is weaker hydrogen bonds and van der Waals forces. Therefore, MPEGMA could be washed away by washing process. If the number of washes increased further, there is no change in the contact angle of the MPEGMA-grafted wool fabric. However, the wetting time of MPEGMA-grafted wool fabric remained to be $0.02 \mathrm{~min}$ after 10 washes. This indicates that MPEGMA-grafted wool fabric has a good durability on the hydrophilic performance due to the covalent bonding of MPEGMA on the surface of wool fibers. The results of wetting properties could confirm that thiol-ene click reaction was catalysed by HRP indirectly.

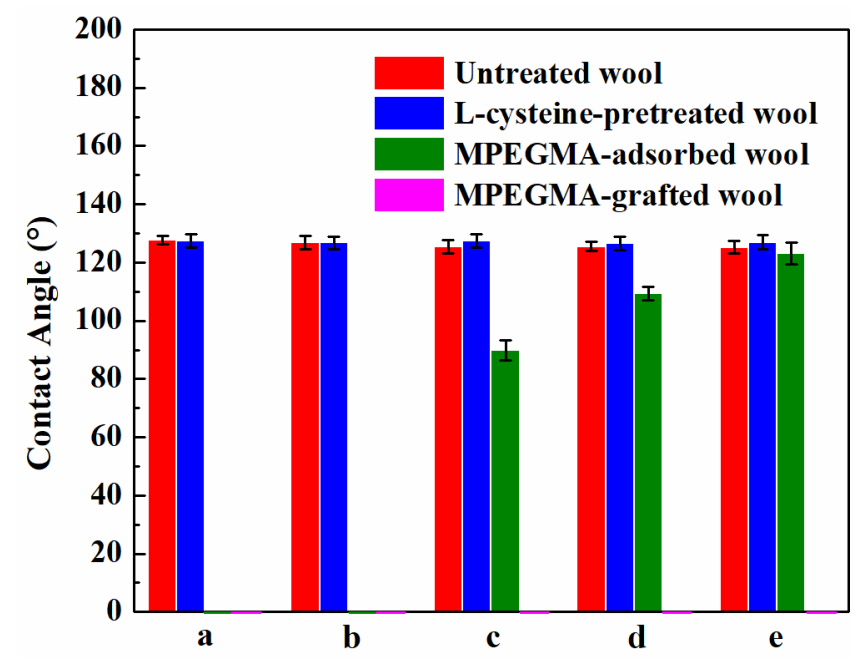

Fig. 7. Contact angle of non-washed (a), 1 time-washed (b), 3 times-washed (c), 5 times-washed (d), 10 times-washed(e) wool fabrics. 


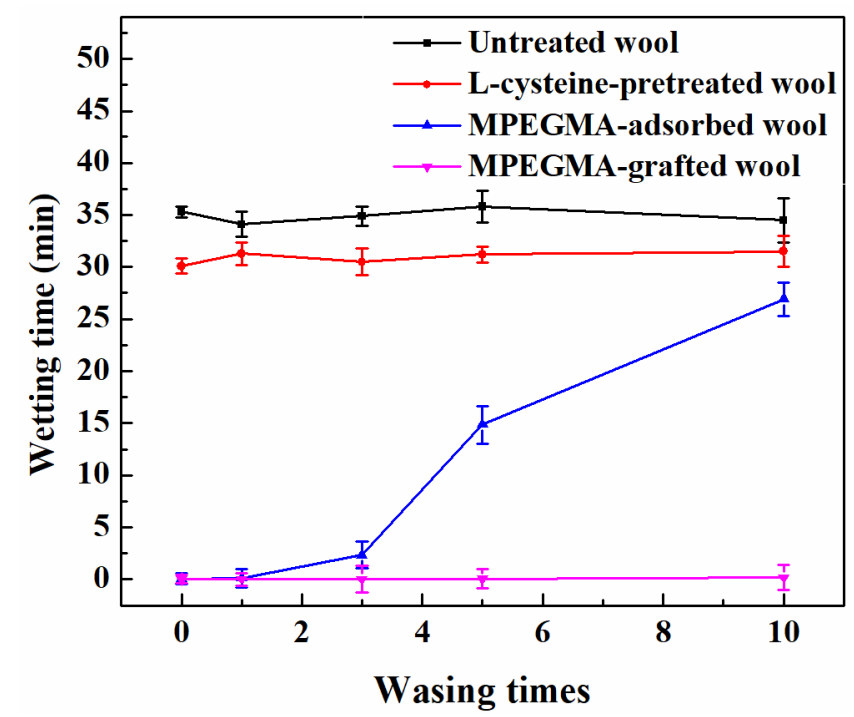

Fig. 8. Wetting time of wool fabrics washed up to 10 times.

\section{Moisture penetrability and regain of MPEGMA-grafted wool fabric}

Moisture penetrability is the property of fabric absorbing and penetrating water vapor. Fig.

9 showed the moisture penetrability and regain of MPEGMA-adsorbed and grafted wool fabric samples compared to the untreated and L-cysteine-pretreated wool fabric samples. Moisture regain of MPEGMA-adsorbed wool was much better than that of untreated wool before washing, but reduced to the level similar to the moisture regain of untreated wool after 10 washes. In case of MPEGMA-grafted wool fabric, though moisture regain also decreased after washing, but still remained higher than that of MPEGMA-adsorbed and untreated wool fabrics. That is because there was no covalent bond between MPEGMA and wool fiber in MPEGMA-adsorbed wool. After washing, MPEGMA decreased from MPEGMA-adsorbed wool, but partial MPEGMA remained in MPEGMA-grafted wool fabric due to the covalent linkage between MPEGMA and wool fiber. The moisture regain of MPEGMA-grafted wool was the best one of the four samples even after washing 10 times. The results of moisture 
penetrability (Fig.9b) show the similar conclusion with that of moisture regain. Moisture regains of MPEGMA-adsorbed wool and MPEGMA-grafted wool were much better than that of untreated wool before washing, but moisture regains of MPEGMA-adsorbed wool was reduced to the level similar to the moisture regain of untreated wool after 10 washes. This is suggested that the moisture regain of wool fabric could be improved with good durability after wool was modified with MPEGMA through thiol-ene click reaction which was catalysed by HRP. The results of moisture penetrability and regain could further verify that wool fabric could be modified with MPEGMA through enzymic thiol-ene click reaction.
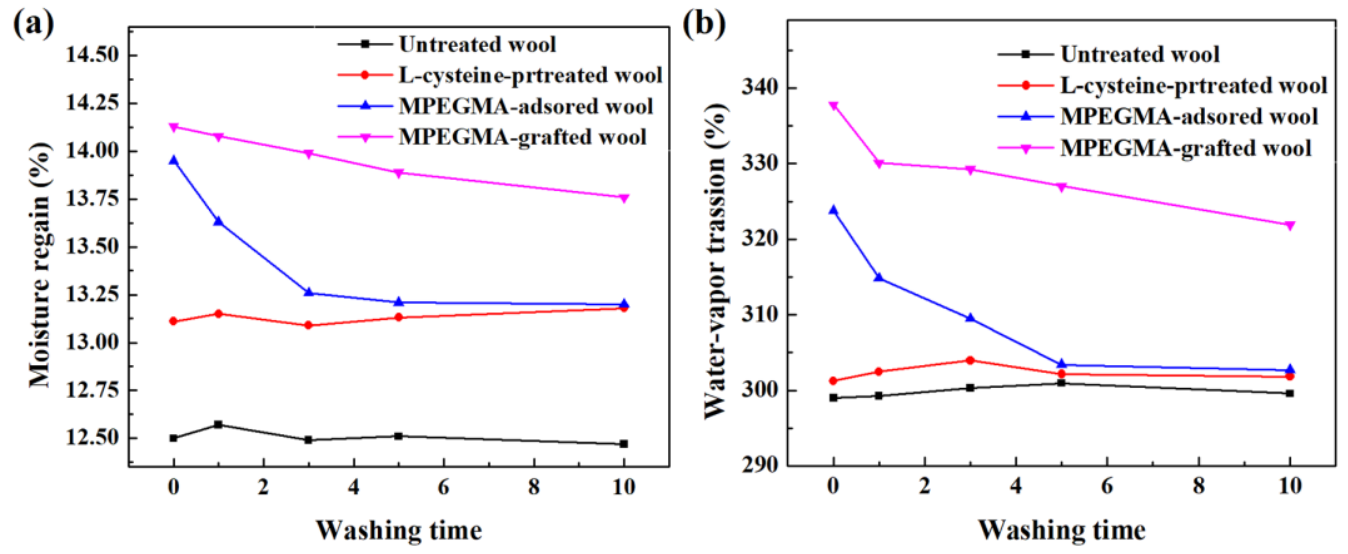

Fig. 9. Moisture regain (a) and penetrability (b) of wool fabrics

\section{Conclusions}

Although there are numerous literature reports on modification or functionalization of keratinous materials like wool, there is lack of sustainable practices in the modification or functional processes due to their negative impact on environmental issues. There was no previous report and knowledge available on the biofunctionalization of wool fibers based on the combination of thiol-ene click reaction and biological catalysis. The current work showed 
that wool fabric was successfully grafted with MPEGMA through thiol-ene click reaction which was catalysed by enzyme Horseradish peroxidase (HRP). L-cysteine, as the model compound to the thiol groups of wool, was used to react with MPEGMA for understanding the mechanism of grafting of MPEGMA onto wool fiber. FT-IR and MALDI-TOF analyses provided theoretical evidence for the grafting of MPEGMA onto wool via thiol-ene click reaction. Raman spectra and XPS analysis confirmed that MPEGMA has been grafted onto wool fiber successfully. The MPEGMA-grafted wool fabric showed significant improvements in wetting properties compared to untreated wool fabric. The water contact angle of MPEGMA-grafted wool fabric was reduced from $127.68^{\circ}$ to $0^{\circ}$. After 10 washes, MPEGMA-grafted wool fabric still remained good wetting property. The water droplet could be soaked into the treated fabric within $12 \mathrm{~s}$. Moisture regains and penetrability of wool fabrics were improved with good durability. The shrink-resist property of wool fibers were also improved. This study provides new insight into novel and sustainable approaches for modification of keratinous or keratin-containing materials.

\section{Acknowledgements}

This work was financially supported by the National Key R\&D Program of China (2017YFB0309200), the National Natural Science Foundation of China (51673087, 31771039), Fundamental Research Funds for the Central Universities (JUSRP51717A), and National first-class discipline program of Light Industry Technology and Engineering (LITE2018-21). Postgraduate Research \& Practice Innovation Program of Jiangsu Province (KYCX19_1876). 


\section{References}

1. Kade, M. J.; Burke, D. J.; Hawker, C. J., The power of thiol-ene chemistry. J Polym Sci Pol Chem 2010, 48 (4), 743-750, DOI: 10.1002/pola.23824.

2. Hoyle, C. E.; Lee, T. Y.; Roper, T., Thiol-enes: Chemistry of the past with promise for the future. J Polym Sci Pol Chem 2004, 42 (21), 5301-5338, DOI: 10.1002/pola.20366.

3. Shin, J.; Matsushima, H.; Chan, J. W.; Hoyle, C. E., Segmented polythiourethane elastomers through sequential thiol-ene and thiol-isocyanate reactions. Macromolecules 2009, 42 (9), 3294-3301, DOI: $10.1021 / \mathrm{ma} 8026386$.

4. Senyurt, A. F.; Wei, H.; Hoyle, C. E.; Piland, S. G.; Gould, T. E., Ternary thiol-ene/acrylate photopolymers: Effect of acrylate structure on mechanical properties. Macromolecules 2007, 40 (14), 4901-4909, DOI: 10.1021/ma062534b.

5. Khire, V. S.; Benoit, D. S. W.; Anseth, K. S.; Bowman, C. N., Ultrathin gradient films using thiol-ene polymerizations. Polym Sci Pol Chem 2010, 44 (24), 7027-7039, DOI: 10.1002/pola.21786.

6. Comí, M.; Lligadas, G.; Ronda, J. C.; Galià, M.; Cádiz, V., Synthesis of castor-oil based polyurethanes bearing alkene/alkyne groups and subsequent thiol-ene/yne post-modification. Polymer 2016, 103, 163-170, DOI: 10.1016/j.polymer.2016.09.057.

7. Levine, A. C.; Heberlig, G. W.; Nomura, C. T., Use of thiol-ene click chemistry to modify mechanical and thermal properties of polyhydroxyalkanoates (PHAs). Int J Biol Macromol 2016, 83 (1), 358-365, DOI: 10.1016/j.ijbiomac.2015.11.048.

8. Luo, X.; Ma, K.; Jiao, T.; Xing, R.; Zhang, L.; Zhou, J.; Li, B., Graphene oxide-polymer composite langmuir films constructed by Interfacial thiol-ene photopolymerization. Nanoscale Res Lett 2017, 12 (1), 99, DOI: 10.1186/s11671-017-1864-8.

9. Yu, D.; Cai, J. Y.; Church, J. S.; Wang, L., Modifying surface resistivity and liquid moisture management property of keratin fibers through thiol-ene click reactions. ACS Appl Mater Inte 2014, 6 (2), 1236-1242, DOI: 10.1021/am405060x.

10. Yi, H.; Wei, W.; Xu, L.; Dan, Y., Surface modification of keratin fibers through step-growth dithiol-diacrylate thiol-ene click reactions. Mater Lett 2016, 178, 159-162, DOI: 10.1016/j.matlet.2016.04.180.

11. Hou, K.; Zeng, Y.; Zhou, C.; Chen, J.; Wen, X.; Xu, S.; Jiang, C.; Pi, P., Facile generation of robust POSS-based superhydrophobic fabrics via thiol-ene click chemistry. Chem Eng J 2017, 332, 150-189, DOI: 10.1016/j.cej.2017.09.074.

12. Ikeda, R.; Sugihara, J.; Uyama, H.; Kobayashi, S., Enzymatic oxidative polymerization of 2,6-dimethylphenol. Macromolecules 1996, 29 (27), 8702-8705, DOI: 10.1021/ma961055h.

13. Bruno, F. F.; Akkara, J. A.; Kaplan, D. L.; Sekher, P. Tripathy, S. K., Enzyme-mediated two-dimensional polymerization of aromatic derivatives on a langmuir trough. Industrial \& Engineering Chemistry Research 1995, 34 (11), 4009-4015, DOI: 10.1021/ie00038a042.

14. Zavada, S. R.; Mchardy, N. R.; Scott, T. F., Oxygen-mediated enzymatic polymerization of thiol-ene hydrogels. J Mater Chem B Mater Biol Med 2014, 2 (17), 2598-2605, DOI: 10.1039/c3tb21794a.

15. Smriti, S.; Fuat, T.; Kathrin, H.; Krystyna, A.; Jürgen, G., Embedding of active proteins and living cells in redox-sensitive hydrogels and nanogels through enzymatic cross-linking. Angew Chem Int Ed Engl 2013, 52 (10), 3000-3003, DOI: 10.1002/anie.201206266. 
16. Liu, R.; Dong, A.; Fan, X.; Qiang, W.; Yu, Y.; Cavaco-Paulo, A., HRP-mediated polyacrylamide graft modification of raw jute fabric. J Mol Catal B-Enzym 2015, 116, 29-38, DOI: 10.1016/j.molcatb.2015.03.004.

17. Zhou, B.; He, M.; Wang, P.; Fu, H.; Yu, Y.; Wang, Q.; Fan, X., Synthesis of silk fibroin-g-PAA composite using $\mathrm{H} 2 \mathrm{O} 2$-HRP and characterization of the in situ biomimetic mineralization behavior. Mat Sci Eng C-Mater 2017, 81, 291-302, DOI: 10.1016/j.msec.2017.08.006.

18. Xu, L.; Zhang, N.; Wang, Q.; Yuan, J.; Yu, Y.; Wang, P.; Fan, X., Eco-friendly grafting of chitosan as a biopolymer onto wool fabrics using horseradish peroxidase. Fiber Polym 2019, 20 (2), 261-270, DOI: 10.1007/s12221-019-8546-3.

19. Zhang, P.; Zhang, N.; Wang, Q.; Wang, P.; Yuan, J.; Shen, J.; Fan, X., Disulfide bond reconstruction: A novel approach for grafting of thiolated chitosan onto wool. Carbohyd Polym 2019, 203, 369-377, DOI: 10.1016/j.carbpol.2018.09.074.

20. Wang, Y. X.; Cao, X. J., Extracting keratin from chicken feathers by using a hydrophobic ionic liquid. Process Biochem 2012, 47 (5), 896-899, DOI: 10.1016/j.procbio.2012.02.013.

21. Chan, S.; Choo, W.; Young, D.; Loh, X., Thixotropic supramolecular pectin-poly (ethylene glycol) methacrylate (PEGMA) hydrogels. Polym 2016, 8 (11), 404, DOI: 10.3390/polym8110404.

22. Chaudhary, A. K.; Critchley, G.; Diaf, A.; Beckman, E. J.; Russell, A. J., Characterization of synthetic polymers using matrix-assisted laser desorption/lonization-time of flight mass spectrometry. Macromolecules 1996, 29 (6), 2213-2221, DOI: 10.1021/ma951047I.

23. Mock, K.; Sutton, C.; Cottrell, J., Sample immobilization protocols for matrix-assisted laser-desorption mass spectrometry. Rapid Commun Mass Sp 1992, 6 (4), 233-238, DOI: $10.1002 / \mathrm{rcm} .1290060402$.

24. Yu, D.; Cai, J. Y.; Liu, X.; Church, J. S.; Wang, L., Novel immobilization of a quaternary ammonium moiety on keratin fibers for medical applications. Int J Biol Macromol 2014, 70, 236-240, DOI: 10.1016/j.ijbiomac.2014.06.025.

25. Ke, G.; Yu, W.; Xu, W.; Cui, W.; Shen, X., Effects of corona discharge treatment on the surface properties of wool fabrics. J Mater Process Tech 2008, 207 (1-3), 125-129, DOI: 10.1016/j.jmatprotec.2007.12.068.

26. Tang, B.; Wang, J.; Xu, S.; Afrin, T.; Xu, W.; Sun, L.; Wang, X., Application of anisotropic silver nanoparticles: multifunctionalization of wool fabric. J Colloid Interf Sci 2011, 356 (2), 513-518, DOI: 10.1016/j.jcis.2011.01.054.

27. Jiugang, Y.; Qiang, W.; Ping, W.; Li, C.; Xuerong, F., Promotional effect of 1-butyl-3-methylimidazolium chloride ionic liquid on the enzymatic finishing of wool. Eng Life Sci 2012, 12 (2), 209-215, DOI: 10.1002/elsc.201100173. 
Abstract Graphic.

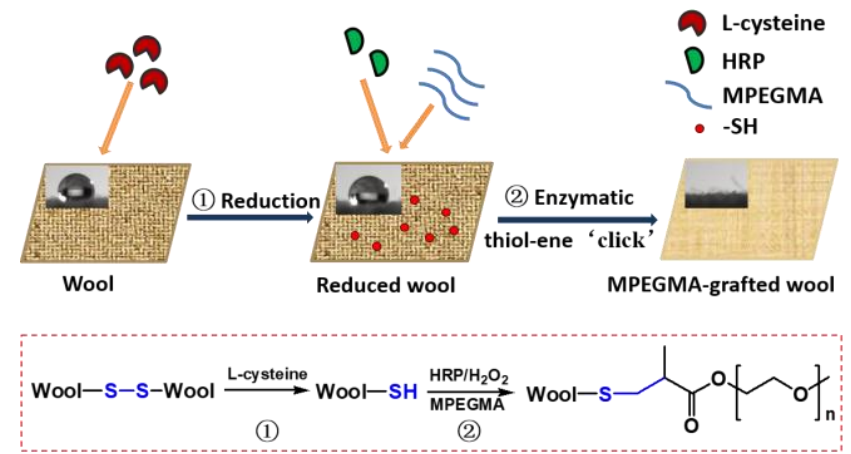

\section{Synopsis}

An environment-friendly strategy for grafting modification of keratin or keratin-containing materials like wool through enzymic thiol-ene 'click' reaction was developed. 